\title{
Cerebrospinal fluid oligoclonal IgG bands in multiple sclerosis: what does it mean?
}

\author{
Bandas IgG oligoclonais no líquido cefalorraquidiano na esclerose múltipla: o que isso significa?
}

Marzia Puccioni-Sohler

PhD; Neurologist, Cerebrospinal Fluid Specialist; Professor at

Federal University of Rio de Janeiro

State (Unirio), Federal University

of Rio de Janeiro (UFRJ) and at

Neurolife, Rio de Janeiro RJ, Brazil.

Correspondence:

Marzia Puccioni-Sohler

Praia do Flamengo $66 \mathrm{~B} /$ conjuntos

219-220 / Bloco B 22210-903 Rio de

Janeiro RJ - Brasil

E-mail:m_puccioni@yahoo.com.br

Conflict of interest

There is no conflict of interest to

declare.

Received 08 July 2012

Accepted 16 July 2012

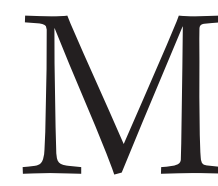

ultiple sclerosis (MS) is a chronic inflammatory demyelinating disease of the central nervous system (CNS). Presence of plaques is the main pathological feature of MS, occurring in myelinated axons within the CNS (brain and spinal cord). MS is classified as relapsing-remitting MS (RRMS) characterized by attacks, whose symptoms occur so suddenly with subsequent partial or complete recovery; primary-progressive MS (PPMS) with progressive symptoms accumulated over time; and secondary-progressive MS (SPMS), after the initial form of RRMS. The most common type of MS is the relapsing-remitting (when attacks may sequelae or not) $)^{1,2}$.

MS diagnosis should be based on clinical picture, but as other CNS disorders may cause similar symptoms, it is necessary to perform additional tests, such as magnetic resonance imaging (MRI) of the brain, evoked potentials, together with an analysis of the cerebrospinal fluid (CSF) $)^{1,2}$.

The CSF analysis is an important tool for MS diagnosis. It reveals mild mononuclear pleocytosis, increased protein levels, and intrathecal synthesis of immunoglobulins. The oligoclonal IgG bands are synthesized in the CNS by B-lymphocytes located near the areas of demyelination, throughout the disease course. Two or more oligoclonal IgG bands found in the CSF, which were not observed in corresponding serum, are a proof of local synthesis. It contributes to the monitoring of inflammatory processes in the CNS. A Brazilian pioneering study showed the presence of CSF oligoclonal IgG bands in $85 \%$ of patients with definite $\mathrm{MS}^{3}$. However, it may found up to $95 \%$ of cases utilizing isoelectric focusing with IgG immunoblotting ${ }^{2}$. Therefore, the test has a high predictive negative value. It does not represent a disease marker, considering that it is not specific for MS, since it may be found in other neurological disorders of the $\mathrm{CNS}^{2-4}$.

Demonstration of oligoclonal IgG bands locally synthesized has been used more recently for the MS prognostic evaluation. Studies haved showed that patients with positive oligoclonal IgG bands have a worse prognosis in comparison to those with negative bands, and the risk of progression to a second attack is doubled, as well as cases of clinically isolated syndrome (CIS) present increased risk of developing $\mathrm{MS}^{5-7}$.

The Journal "Arquivos de Neuro-psiquiatria" presents a very interesting study of Juan Ignacio Rojas et al. ${ }^{8}$ on the association between the presence of oligoclonal bands in CSF of RRMS patients and brain atrophy (seen on MRI), in the onset of the disease. The work was conducted at the MS Center at the Hospital Italiano de Buenos Aires, Argentina, from June 2006 to June 2010. Of a total of 40 patients, 29 (72.5\%) had positive oligoclonal IgG bands in $\mathrm{CSF}$ and showed reduction in the brain gray substance. The authors suggest that the presence of oligoclonal bands in CSF predicts a worse disease course in MS patients, considering that it is more frequently associated with the presence of neurodegenerative lesions in the initial stage of the disease.

In conclusion, the examination of oligoclonal IgG bands is strongly recommended for MS diagnosis, and it seems to be of value as a prognostic factor. 


\section{References}

1. Polman CH, Reingold SC, Edan G, et al. Diagnostic criteria for multiple sclerosis: 2005 revisions to the "McDonald Criteria". Ann Neurol 2005;58:840-846.

2. Hans Link. Oligoclonal bands in multiple sclerosis cerebrospinal fluid: An update of methodology and clinical usefulness. J Neuroimmunol 2006;180:17-28.

3. Puccioni-Sohler M, Passeri F, Oliveira C, Brandão CO, PapaizAlvarenga R. Multiple sclerosis in Brazil. Analysis of cerebrospinal fluid by standard methods. Arq Neuropsiquiatr 1999;57:927-931.

4. Awad A, Hemmer B, Hartung HP, Kieseier B, Bennett JL, Stuve O. Analyses of cerebrospinal fluid in the diagnosis and monitoring of multiple sclerosis. J Neuroimmunol 2010;219:1-7.
5. Joseph FG, Hirst CL, Pickersgill TP, Ben-Shlomo Y, Robertson NP, Scolding NJ. CSF oligoclonal band status informs prognosis in multiple sclerosis: a case control study of 100 patients. J Neurol Neurosurg Psychiatry 2009;80:292-296.

6. Siritho S, Freedman MS. The prognostic significance of cerebrospinal fluid in multiple sclerosis. J Neurol Sci 2009;279:21-25.

7. Tintore M, Rovira A, Rio J, et al. Do oligoclonal bands add information to MRI in first attacks of multiple sclerosis? Neurology 2008;70:1079-1083.

8. Rojas JI, Patrucco L, Tizio S, Cristiano E. Oligoclonal bands in the cerebrospinal fluid and increased brain atrophy in early stages of relapsing-remitting multiple sclerosis. Arq Neuropsiquiatr 2012;70:574-577. 